\title{
Study on the Challenges of China's Innovative Country Construction -From the Perspective of National Innovation Capability and Competitiveness
}

\author{
Gou Ling ${ }^{1 . a,{ }^{*}}$, Li Shiming ${ }^{2, b}$, Liu Hui ${ }^{3, c}$, Tang Min ${ }^{4, d}$ and Shen Yan ${ }^{5, e}$
}

${ }^{1}$ School of Management and Economics, University of Electronics Science and Technology of China, Chengdu, Sichuan, P.R. China

${ }^{2}$ School of Management and Economics, University of Electronics Science and Technology of China, Chengdu, Sichuan, P.R. China

${ }^{3}$ School of Public Policy \& Management, Tsinghua University, Beijing, P.R. China

${ }^{4}$ College of Management Science, Chengdu University of Technology, Chengdu, Sichuan, P.R. China

${ }^{5}$ School of Management and Economics, University of Electronics Science and Technology of China, Chengdu, Sichuan, P.R. China

agouling_0827@126.com, ${ }^{b}$ lism@uestc.edu.cn, ${ }^{9}$ huiliu@tsinghua.edu.cn, ${ }^{d}$ tangm@cdut.edu.cn, esheny@uestc.edu.cn

${ }^{*}$ Gou Ling

Keywords: Innovative Country, National Innovation Capability, National Competitiveness, Innovation Deviation Index.

Abstract. To make China an Innovative Country is an important target in recent years. Based on the Global Competitiveness Index (GCI) and Global Innovation Index (GII), this paper studies the current situation of China's innovative country construction. Furthermore, the innovation deviation index (IDI) is constructed, and the IDI of China is compared with seven typical innovative countries from the perspective of matching degree between national innovation capability and competitiveness. The research shows that, first of all, China has not yet become an innovative country. Secondly, China's IDI is significantly higher than the annual average of seven countries. The reason is that the promotion of China's GII is not driven by the promotion of core indicators, it is not enough to have a great impact on GCI, and GII overestimates China's innovation capability. Finally, from the above analysis, this paper gives suggestions on how to improve China's innovation capability and competitiveness.

\section{Introduction}

In May 2006, the Chinese government declared that China would make an innovative country by 2020. Since then, China's economy has maintained rapid development. In 2010, China's GDP surpassed Japan and ranked second in the world. So, has China already become an innovative countries? As national competitiveness and innovative capability are the most important factors to support national economic and technological development, what is the level of China's compared with innovative countries?

In terms of national competitiveness and innovation capability, many international organizations have conducted in-depth research and achieved fruitful results ${ }^{[1]}$. Among them, the Global Competitiveness Index (GCI) by World Economic Forum, the World Competitiveness Index (WCI) by Lausanne International Management Institute, Global Innovation Index (GII) by Cornell University, World Intellectual Property Organization, and European Business School, National Innovation Index (NII) by China National Institute of Science and Technology Development Strategy ${ }^{[2]}$ are the authoritative ranks of global competitiveness and innovation capability. 
Domestic scholars have different opinions on whether China has become an innovative countries or not based on the above-mentioned ranks. For example, H. Y. $\mathrm{Xu}^{[3]}$ believes that China is an innovative country, while W. J. Cui ${ }^{[4]}$ and C. Y. Liu $^{[5]}$ believe that China is still an innovative follower. On innovation capability, H. F. $\mathrm{Liu}^{[6]}$, G. B. Huang ${ }^{[7]}$, B. G. Chen ${ }^{[8]}$, and S. Qi ${ }^{[9]}$ compared the innovation capabilities of major economies, showing that China's innovation capability continues to improve, but with low quality and structural imbalance in innovation input and output. On national competitiveness, C. Xing ${ }^{[10]}$ and J. J. Huang ${ }^{[11]}$ studied the developed and emerging economies' competitiveness, it shows that China needs to improve education, infrastructure and innovation ecology.

The reason for the disagreement on whether China is an innovative countries or not, is partly due to the different ranks of China's competitiveness and innovation capability. For example, in 2018, China's GCI and GII are 28th and 17th respectively, and there are 11 huge gaps between the two. So, what are the reasons?

Based on the above two issues, this paper uses the GCI and GII to build an innovation deviation index (IDI) from the perspective of national innovation capability and competitiveness, and analyzes whether China has become an innovative countries. And based on China's innovation index of past years to predict the possibility of China becoming an innovative country by 2020, and analyze the reasons for the differences between China's GCI and GII.

\section{Research design}

There are currently 20 innovative countries around the world. Therefore, 'top 20' can be a benchmark to study the possibility that China will become an innovative countries by 2020 . Based on the 2011 2018 GCI and GII, this paper uses the exponential smoothing method to predict China's innovation index by 2020 .

Innovation is the source of national competitiveness, and the improvement of national competitiveness is also conducive to innovation. Taking innovation as the core driving force for economic and social development and forming a strong national competitiveness is a typical feature of an innovative country. Therefore, studying the relationship between national competitiveness and innovation capability is of guiding significance for promoting China's innovative country construction. In order to measure the degree of correlation between the two, this paper constructs an innovation deviation index based on GII and GCI, as shown in formula (1):

$$
\mathrm{y}_{i t}=\frac{G C I_{i t}}{G I I_{i t}}
$$

Where $G C I_{\mathrm{i} t}$ is the GCI of Country $i$ in year $t ; G I I_{\mathrm{i} t}$ is the GII of Country $i$ in year $t \circ y_{i t}$ is the IDI of Country $i$ in year $t$.

Among the 20 innovative countries, 7 countries are with a population over 10 million, and R\&D investment are at top 20 worldwide, they are U.S, Japan, Germany, South Korea, France, the U.K, and Canada. The 7 countries are compared with China to analyze the IDI.

\section{Empirical analysis}

\subsection{Evaluation of China's innovative country construction based on GCI and GII}

Table 1. China's GCI and GII

\begin{tabular}{cccccccccc}
\hline Year & & 2011 & 2012 & 2013 & 2014 & 2015 & 2016 & 2017 & 2018 \\
\hline \multirow{2}{*}{ GCI } & Rank & 26 & 29 & 29 & 28 & 28 & 28 & 27 & 28 \\
& Score & 4.9 & 4.83 & 4.84 & 4.89 & 4.89 & 4.89 & 5 & $72.6^{1}$ \\
\hline \multirow{2}{*}{ GCI-Innovation } & Rank & 29 & 33 & 32 & 32 & 31 & 30 & 28 & 24 \\
Capability & Score & 3.9 & 3.8 & 3.9 & 3.9 & 3.9 & 4.0 & 4.1 & 64.4 \\
\hline \multirow{2}{*}{ GII } & Rank & 29 & 34 & 35 & 29 & 29 & 25 & 22 & 17 \\
& Score & 46.43 & 45.4 & 44.66 & 46.57 & 47.47 & 50.57 & 52.54 & 53.06 \\
\hline
\end{tabular}

(1) The scores use percentile system in 2018. 
From Table 1, the following conclusions can be obtained:

(1) During 2011 2018, China's GCI and GII are within top 30, indicating China's competitiveness and innovation capability have been stable in the global upper and middle levels.

(2) During 2011 2018, China's GCI and GII have improved, but the improvement has not led to a 'level jump' in driving factors: China is currently in the transition from efficiency-driven period to innovation-driven period.

\subsection{Analysis based on IDI}

According to formula (1), during 2011 2018, the average annual IDI of 7 countries is 1.13, which is only $13 \%$ beyond the optimal value 1 . For them, there is a high degree of matching between their innovation abilities and competitiveness, and the innovation capability is slightly ahead of competitiveness. It indicates that innovative countries take innovation as the core driving force to promot national competitiveness.

In Figure 1, China's IDI keeps increasing since 2013. In 2016, it was close to 1.13, and then increased to a maximum of 1.65 in 2018, exceeding the annual average of 7 countries by $46 \%$. It can be seen that with China's innovation capability's continuous promotion, its matching degree with national competitiveness steadily deteriorated.

From the ranks of other indicators of GII, China leads on market size, R\&D investment, patent and trademark applications, import and export of high-tech products. It is abvious that these are aggregate indicators, divided by China's huge population, they will lose the edge. For example, in 2018, China's patent and trademark applications ranked first and third in GII, while ranked 32nd and 45th respectively per million population in GCI. As for quality, China's patents are mainly trademark patents, industrial design patents, utility model patents, core technology patents are much less. It has characteristic of large quantity and poor quality. China's research funding reached alomst 2 trillions yuan in 2018, ranked second after USA, but the proportion of fundamental research only accounts for 5.5\%, far lower than innovative countries (15\% 20\%), which resulting in insufficient research on key common technologies, cutting-edge leading technologies, and disruptive technological innovations, and few vital breakthroughs have been made. The large import and export of high-tech products is because China's manufacturing industry is mostly just assembly. Therefore, there is possibility that GII overestimates China's innovation capability.

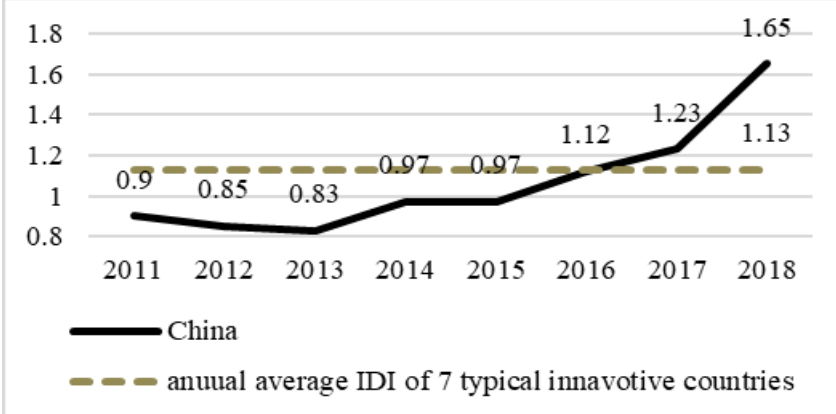

Figure 1. IDI of China and anuual average IDI of 7 typical innavotive countries

The improvement of China's innovation capability is not enough to have a major impact on competitiveness, and the overstimation of innovation capability explains the gap between China's GII and GCI. China's innovative capability and competitiveness still face many challenges, such as the innovative talents, fundamental research and innovative environment.

\subsection{China will become an innovative country by 2020}

In Table 1, from 2013 to 2018, China's GII and GCI innovation capability rank kept steady increasing, and it is abvious that they both will continue to increase to top 20 by 2020 (as shown in Figure 2), which indicates that China will become an innovative country by 2020 . 


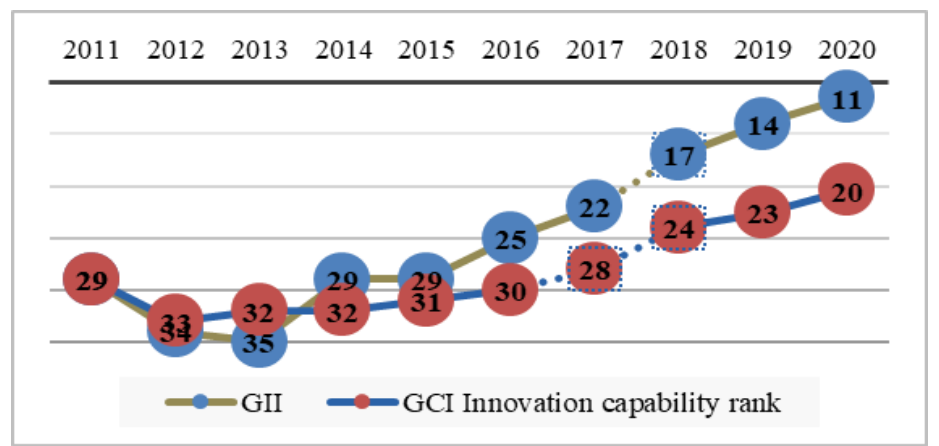

Figure 2. China's GII and GCI innovation capability rank

\section{Conclusions and Suggestions}

\subsection{Conclusions}

This paper answers the question of whether China has become an innovative country or not based on GCI and GII. From the perspective of innovation capability, the possibility of China's becoming an innovative country by 2020 is predicted. China still faces many chalenges, and the reasons are analyzed. From the above analysis, three conclusions are obtained:

Firstly, GCI and GII both indicate that China has not yet become an innovative country.

Secondly, China's IDI steadily deteriorated, which indicates that China's competitiveness and innovation capability still face many challenges. The improvement of China's GII is not driven by the improvement of core indicators, therefore, it is not enough to promote the GCI. And the overestmation of China's innovation capability further increases the gap between GII and GCI.

Thirdly, GCI innovation capability rank and GII both indicate that China can enter the top 20 by 2020, which means that China's goal of become an innovative country by 2020 can be achieved.

The above conclusions provide guidance for China to recognize the prensent, prospect and challenges of China's innovative country construction, and also remind us to find out the 'bottleneck' of China's innovation capability and competitiveness.

\subsection{Suggestions}

Firstly, in order to cultivate innovative talents, China's higher education should be improved. Talents are the first driving force for innovation. It is necessary to reform China's higher education system, improve the mode of talent training in colleges and universities.

Secondly, China should more focous on fundamental research, which is significant important to scientific and technological development.

Lastly, China should accelerate the reform of conomic development model and transform into a resource-saving and environment-friendly economy, achieving energy conservation and emission reduction.

\section{References}

[1] W. Gen, T. Wang, Review and Prospect of National Innovation System Development Evaluation, Technological Economy, 2014, 33 (04): 13-18.

[2] China Academy of Science and Technology Development Strategy, National Innovation Index 2015, Beijing: Science and Technology Literature Publishing House, 2016.

[3] H. Y. Xu, X. Zhang, et al, Looking at the rising trend of China's innovation from the GII report, World Science and Technology Research and Development, 2017, 39 (05): 391-400.

[4] W. J. Cui, Y. L. Chen, Monitoring and analysis of China's innovative country constructionbased on the GII, Science \& Technology Progress and Policy, 2013, 30 (20): 118-123. 
[5] C. Y. Liu, By 2020, China will make an innovative country - based on the GII, Macroeconomic management, 2017 (01): 34-37.

[6] H. F. Liu, Y. J. Sun, Perspective of China's Innovation Capability from Major International Evaluation Reports, Research on Science and Technology Management, 2017, 37 (15): 10-14.

[7] G. B. Huang, International Comparison and Enlightenment of Innovation Ability of Major Global Economies Based on GII, Science and Technology Management, 2014 (2): 143-153.

[8] B. G. Chen, H. T. Yin, Comparative Analysis of China's Innovation Capability based on GII, Research on Science and Technology Management, 2016, 36 (23): 32-37.

[9] S. Qi, L. C. Liu, Analysis of China's Innovation Capability Based on Global Typical Innovation Index, World Science and Technology Research and Development, 2018, 40 (01): 71-84.

[10]C. Xing, L. Shi, A comparative analysis China based on 2016-2017 GCR, Global Science, Technology and Economy Outlook, 2017, 32 (01): 60-72.

[11]J. J. Huang, Z. J. Zhang, J. L. Tian, F. P. Lu, F. Q. Li, and X. B. Fu, The advantages and disadvantages of China's competitiveness from GCI, Global Science, Technology and Economy Outlook, 2019, 34 (02):56-63. 